\title{
MENCINTAI KELUARGA Mengahayati Keadilan dan Belas Kasih
}

\author{
Largus Nadeak*
}

\begin{abstract}
Abstrak
Tantangan, masalah, dan krisis dalam keluarga dengan bervariasi jenis sudah lama terjadi dan akan berlanjut. Aturan yang sudah dirumuskan dalam masyarakat dan dalam umat Gereja bisa membantu keluarga, tetapi cenderung menghukum keluarga yang bersalah, sehingga kurang membantu keluarga untuk memperbarui diri. Paus Fransiskus dalam Bulla Misericordiae Vultus (Wajah Kerahiman) dan Anjuran Apostolik Paska Sinode Amoris Laetitia (Kegembiraan Cinta) mengajak umat agar setiap keluarga bergegas menghayati kekudusan sakramental perkawinan dalam kehidupan real, sehingga bergembira saling mencintai dengan keadilan dan belas kasih. Daya belas kasih ilahi yang hidup dalam keluarga sakramental akan bangun kalau keluarga memaafkan kekurangan dan meneguhkan kebaikan sehingga nyata dialami suka cita yang bisa mengatasi tantangan dan masalah. Dengan membaca dan mendengar Sabda Allah, keluarga mendapat inspirasi dari pengalaman keluarga beriman untuk menghayati keterlibatan Allah. Dengan berdoa bersama di keluarga dibantu media yang tersedia dewasa ini, serta kreatif menggunakan waktu secara bersama dalam kesibukan harian akan mendatangkan berkat baru untuk keluarga.
\end{abstract}

Kata-kata kunci: Allah, keluarga, belas kasih, adil, cinta, sakramen, baru.

\section{Pengantar}

“I love my family!" Ungkapan berharum cinta keluarga ini sudah biasa kedengaran. Keharuman cinta kadang kurang memancar dan kurang dirasakan keluarga karena anggota keluarga itu sendiri diserap oleh aktivitas sehari-hari. Ungkapan "I love my family!" berpesan bagi saya ketika saya lihat tertulis di kemeja rombongan keluarga yang sengaja mencari hari khusus berkumpul (rekoleksi) untuk menyegarkan relasi cinta keluarga. Dengan menghayati ungkapan berdaya ini, orang tua merawat janji sakramental perkawinan secara lestari, dan mewariskannya pada setiap anggota keluarga (anak yang sudah berkeluarga dan cucu) agar berusaha menghayati cinta, keadilan, dan belas kasih. Ikatan belas kasih sakramental memampukan keluarga untuk mengatasi tantangan dan masalah keluarga yang muncul dalam kesibukan sehari-hari, yang kadang menyeret anggota pada 
kepentingan pribadi; dan juga mengatasi masalah yang terjadi dalam masyarakat di zaman yang berubah saat ini.

Panggilan untuk mendalami penghayatan keadilan dan belas kasih dalam keluarga diserukan oleh Paus Fransiskus dalam Bulla Pemberitahuan Yubileum Luar Biasa Kerahiman Misericordiae Vultus (Wajah Kerahiman), 2015. Seruan inspiratif ini diteguhkannya dalam Anjuran Apostolis Paska Sinode Amoris Laetitia, 2016, agar setiap keluarga bergegas menghayati kekudusan sakramental perkawinan dalam kehidupan real.

\section{Tantangan dan Masalah Keluarga}

Realitas keluarga Katolik secara umum dewasa ini bisa kita lihat langsung dalam pengalaman nyata sehari-hari di lingkungan kita. Satu pengalaman menggugah untuk saya, ketika saya mengadakan pertemuan tetang "hidup bermoral" untuk beberapa pemuka umat Katolik. Di saat pause pun (pertanda masalah mendesak dan penting), peserta pertemuan melemparkan beberapa pertanyaan yang berhubungan dengan masalah yang makin rumit sehubungan dengan perkawinan dan hidup berkeluarga. Menarik untuk saya karena para pemuka umat tersebut ditantang untuk mencermati masalah keluarga dan berusaha untuk memecahkan dan mengatasi masalah tersebut. Realitas keluarga Katolik kita kenal lebih jelas dari hasil penelitian yang bisa dipertanggungjawabkan. Hasil penelitian di Keuskupan Agung Medan menggambarkan bahwa realitas keluarga Katolik sedang mencemaskan. Dikategorikan mencemaskan karena realitas berada di bawah standar kebiasaan hidup keluarga beriman. Ada beberapa situasi menantang ${ }^{1}$ yang perlu mendapat perhatian. Makin menonjol bahwa

${ }^{1}$ Keadaan keluarga Katolik yang perlu dibenahi di Keuskupan Agung Medan, antara lain: pengetahuan dan penghayatan iman masih lemah, pendidian dan nilai dalam keluarga dianggap tidak penting, pemahaman dan penghayatan perkawinan kurang, hubungan keluarga dengan masyarakat sekitar sering berdampak negatif, dan kebersamaan dalam keluarga masih sangat kurang, keluarga sangat mudah terbawa arus perubahan zaman, peran orang tua dalam keluarga sangat kurang dan lemah, keadaan ekonomi umumnya lemah karena kurang kreatif dan kurang etos kerja, keluarga umumnya lebih mementingkan adat dari pada agama, perhatian pada anak remaja kurang, pendidikan seksualitas masih dianggap tabu, hubungan dengan keluarga besar tidak selalu positif, usaha untuk menanamkan panggilan untuk imam dan Lembaga Hidup Bakti berkurang. Lihat, Sekretariat Sinode VI, Keadaan Keluarga Katolik di Keuskupan Agung Medan, Hasil Penelitian dan Jajak 
kebersamaan dan komunikasi keluarga cukup minim. Anggota keluarga sibuk di luar rumah dan sibuk juga di dalam rumah. Afeksi bersama minim, kegiatan bersama penyubur cinta keluarga menipis, yang menebal adalah ketertutupan dalam kesendirian. Sikap individualisme semakin subur, sehingga anggota keluarga semakin sulit memberi diri satu sama lain. ${ }^{2}$ Peran orang tua makin lemah, makin ketinggalan zaman. Anak tidak merasa nyaman bersama orang tua. Keluarga sangat mudah dibawa arus perubahan zaman dan dikuasai oleh alat-alat komunikasi modern pemudah rasa senang dan pengikis daya juang. Terjadi bahwa beberapa pasangan suami isteri bercerai. Perceraian suami isteri berakibat pada "perceraian" anak-anak mereka. Ada anak yang ikut bersama ayahnya, yang lain ikut bersama ibunya. Masalah ini berpanjang karena penghayatan keadilan dan belas kasih kurang diperhatikan.

Menurut Herbert Anderson, krisis keluarga yang terjadi saat ini merupakan timbunan dari krisis masa lalu yang tak pernah selesai diatasi, ditambah lagi krisis lain yang menonjol yang diamati oleh Paus Fransiskus. $^{3}$

a. Krisis nilai: Sekitar tahun 1960 muncul krisis nilai. Saat itu muncul hidup sosial yang menggugat tradisi dan senang tanpa aturan. Penghargaan pada kesepakatan menipis sehingga terjadi ketidakpastian dalam keluarga. Otoritas orang tua pada anak menipis sehingga orang tua dan anak agak gamang menghadapi tekanan-tekanan sosial dan pluralitas nilai.

b. Krisis kompetensi: Sejak zaman industrialisasi, pengelolaan pekerjaan tidak di rumah lagi, muncul pabrik-pabrik dan biro-biro.

Pendapat, Keuskupan Agung Medan, Pematangsiantar 2016, hlm. 97-125: lihat juga Richard Sinaga, "The Gospel of the Family, Panggilan dan Perutusan Keluarga Gereja menurut Katolik dan Aplikasinya di Keuskupan Agung Medan", dalam Sekretariat Sinode VI, Instrumentum Laboris dan Makalahmakalah, Keluarga Katolik sebagai Gereja Kecil, Pematangsiantar 2016, hlm. 238-241.

2 Sekretariat Sinode VI, Keadaan Keluarga Katolik... hlm. 97-125; diperkaya oleh pengamatan Paus Fransiskus dalam Paus Fransiskus, Anjuran Apostolis Paska Sinode Amoris Laetitia (Kegembiraan Cinta), Roma 2016, no. 33.

${ }^{3}$ Krisis a sampai d menurut Herbert Anderson, "The Family under Stress, A Crisis of Purpose", dalam Paul Jersild and Dale Johnson (ed), Moral Issues and Christian Respons, New York: The Dryden Press 1988, hlm. 84-87; Krisis e dan $\mathrm{f}$ tambahan dari Paus Fransiskus, Anjuran Apostolik Paska Sinode Amoris Laetitia (Kegembiraan Cinta), Roma 2016. 
Orang tua pergi dari rumah di pagi buta dan pulang pada larut malam. Akibat krisis ini, pendidikan anak tidak diemban orang tua lagi tetapi diserahkan pada sekolah, badan sosial, dan pembantu. Keluarga kehilangan kompetensinya dalam mendidik anak. Melemahnya machismo dan naiknya kesadaran feminisme turut mempengaruhi crisis of competence ini. Laki-laki dan perempuan memang bermartabat sama, dan bukan yang satu mendominasi yang lain, namun ketidakjelasan peran (bapa, ibu, anak laki dan perempuan) di keluarga turut menimbulkan masalah.

c. Krisis perspektif: Keluarga kurang memberi perhatian pada generasi berikut. Perhatian keluarga yang kurang pada nilai masa lalu (sejarah) akan mengakibatkan keluarga tersebut kurang perhatian, dan kurang memiliki perspektif ke depan. Krisis perspektif akan menimbulkan krisis harapan dan cita-cita dalam keluarga.

d. Krisis tujuan: Sasaran keluarga semakin tidak jelas. Cinta dan kebahagiaan bersama diabaikan karna anggota keluarga menyerap dan mengangkat kecenderungan-kecenderungan sosial menjadi kebiasaan keluarga. Akibatnya keluarga kurang merawat nilai kebersamaan internal, kurang mengikuti jejak Allah yang meneguhkan, menyambut dan mengampuni. ${ }^{4}$

e. Krisis komunikasi alamiah: Penggunaan sarana komunikasi yang makin dominan dewasa ini mengakibatkan komunikasi tatap muka alamiah di keluarga makin tipis. Anggota keluarga sibuk menggunakan media sosial di dalam dan di luar rumah sehingga komunikasi akrab dan afektif tidak terjalin dengan baik.

f. Krisis belas kasih: Masalah yang terjadi dalam keluarga tidak diselesaikan dengan jiwa belas kasih, pada hal dari dulu belas kasih dan pengampunan gencar dipromosikan oleh imam dan umat. Penerapan aturan dan hukuman pada keluarga bermasalah lebih menonjol dari pada membereskan masalah tersebut.

4 Marife Ramos Gonzalez, "The Family and Moral Decision: How Should the Christian Family Respon to the New Moral Challenges of Today?" dalam Lisa Sowle Cahil and Dietmar Mieth (ed), The Family-Concilium (1995/4, Maryknoll, Orbis Books, 1995, hlm., 66. 


\section{Keluarga Sakramental}

Paus Fransiskus mengatakan bahwa krisis yang terjadi saat ini hendaknya tidak menjadi mencemaskan belaka, tetapi justru untuk menguatkan keluarga dan umat agar belajar mengikuti seruan hati nurani yang baik dan benar. ${ }^{5}$ Gereja mengajarkan bahwa keluarga Katolik yang baik adalah satu persekutuan kasih yang terdiri dari pribadi-pribadi yang beriman, yang saling menerima, mendukung, mencintai dan menghargai perbedaan masing-masing. Janji pernikahan yang diucapkan oleh suami istri dan diteguhkan oleh imam (diakon) adalah janji sakramental. Janji ini real sebagai sakramen kalau keluarga menghayati panggilan sebagai keluarga adil dan berbelas kasih. Persekutuan kasih itu diadakan dan diberkati oleh Allah dan diangkat ke status sakramen yang melambangkan kesatuan dan cinta Yesus Kristus kepada Gereja. Oleh karena itu, sifatnya tidak terbatalkan dan tidak terceraikan seperti kesatuan dan keabadian kasih Kristus kepada Gereja-Nya. Kalau kasih Kristus semakin tertanam di dalam hati pasangan, mereka akan mengutamakan yang dikasihi. Dalam sakramen perkawinan cinta berarti orang melepaskan diri untuk pasangannya dan bersedia mati bersamanya. ${ }^{6}$ Di dalam keluarga Katolik Kristus selalu hadir dan mencurahkan rahmat-Nya kepada setiap anggota keluarga baik dalam suka maupun dalam duka. Cinta Allah dicurahkan dan dianugerahkan ke suami isteri dan ke keluarga melalui kelahiran dan perkembangan anak-anak. Tugas hakiki dari pasangan suami isteri ialah mengabdi kepada kehidupan melalui kehadiran dan pembinaan anakanak.

Sebagai bagian penting dalam masyarakat, keluarga ikut serta dalam pengembangan hidup sosial, terutama melalui kelahiran, pendidikan, serta penyaluran nilai-nilai sosial pada anak. Saat ini jumlah anak dalam keluarga harus mendapat perhatian agar kualitas dan kuantitas penghayatan sakramen perkawinan berlangsung baik. Keluarga Katolik berperan penting dalam kehidupan dan misi Gereja melalui 3 tugas: a) mewujudkan persekutuan yang beriman dan mewartakan Injil; b) membangun sebuah persekutuan kasih yang berdialog dengan Allah melalui hidup liturgi sakramental, doa-doa dan

${ }^{5}$ Amoris Laetitia, no. 37.

6 Cletus Groenen, Perkawinan Sakramental, Anthropologi dan Sejarah Teologi, Sistematik, Spiritualitas, Pastoral, Yogyakarta: Kanisisus, 1993, hlm. 409410 . 
devosi; c) menghidupi sebuah persekutuan yang melaksanakan pengabdian kepada sesama. ${ }^{7}$

Dalam perkawinan sakramental Allah hadir dan berperan dalam keluarga sehingga saling mencintai dan melihat kenyataan dengan mata ilahi dan mata sosial. Keluarga beriman berdaya menelusuri kenyataan senang dan derita dalam harap dan cinta. Penghayatan iman yang dalam akan menjadikan keluarga berbelas dan murah hati. Sakramen perkawinan memperkuat dan menopang mereka ketika ragu-ragu serta ketika dalam kelemahan. ${ }^{8}$

\section{Menghayati Keadilan dan Belas Kasih}

Untuk mengatasi krisis dan mengurangi masalah yang terjadi dalam keluarga, dengan belajar mengikuti seruan hati nurani yang baik dan benar, penghayatan keadilan dan belas kasih perlu dipromosikan. Sikap adil berbelas kasih membantu keluarga memperbaiki kekurangan dan kesalahan yang terjadi, bukan sebaliknya menghakimi dan memperbesar permasalahan yang mengakibatkan anggota menjadi "domba" yang hilang total.

\section{Menghayati Keadilan}

Sabda Allah berisi banyak nilai keadilan. "Segala tulisan yang diilhamkan Allah memang bermanfaat untuk mengajar, untuk menyatakan kesalahan, untuk memperbaiki kelakuan, dan untuk mendidik orang dalam kebenaran/keadilan." (2Tim. 3:16). "Tuhan telah memperkenalkan keselamatan yang dari pada-Nya, telah menyatakan keadilan-Nya." (Mzm. 98:2). Keadilan Tuhan adalah belas kasihan dan kaya akan rahmat. Keadilan Tuhan adalah kebebasan dan keselamatan. Dalam hidup sehari-hari manusia dipanggil untuk mencari Kerajaan Allah dan keadilan-Nya (Mat. 6:33) ${ }^{9}$

Keadilan adalah salah satu keutamaan moral kristen yang diperoleh dengan membiasakannya. Keadilan adalah keutamaan yang

7 Richard Sinaga, “The Gospel of Family...", hlm. 236 - 237.

${ }^{8}$ Maurice Eminyan, Teologi Keluarga, Yogyakarta: Karinisus, 2001, hlm. 83-85; Gaudium et Spes, dalam Dokumen Konsili Vatikan II. Diterjemahkan oleh R. Hardawiryana. Jakarta: Dokumentasi dan Penerangan KWI - Obor, 1993, no. 48.

9 Largus Nadeak, Topik-topik Teologi Moral Fundamental, Memahami Tindakan Manusiawi dengan Rasio dan Iman, Medan: Bina Media Perintis, 2015, hlm. 156. 
dimiliki orang karena secara konstan dan dengan kemauan tetap memberikan kepada setiap orang apa yang menjadi hak dan miliknya. Dengan memberikan hak orang lain, seseorang menunaikan tanggung jawab, dan orang yang menerima haknya juga dipanggil menunaikan tanggung jawab. ${ }^{10}$

Keadilan adalah pintu masuk ke hidup berbelas kasih. Keluarga beriman wajib melangkah lebih jauh untuk mencapai tujuan yang lebih tinggi, yaitu kedamaian dalam kasih Allah. Jalan ke situ adalah pengampunan dan pemberian maaf. ${ }^{11}$ Keadilan yang berbelas kasih dengan indah dituturkan dalam Kitab Suci. Salah satu penuturan yang berpesan adalah pengalaman Yusuf dalam Kitab Keluaran. Peristiwa pertemuan Yusuf dengan para saudaranya di Mesir menjadi pengalaman keadilan dan belas kasih berkeluarga berinspirasi ilahi. Ketika Yusuf mengatakan pada para saudaranya agar mereka membawa saudara mereka yang bungsu, dia mendengar para saudaranya berkata, "Betul-betullah kita menanggung akibat dosa kita terhadap adik kita itu: bukankah kita melihat bagaimana sesak hatinya, ketika ia memohon belas kasihan kepada kita, tetapi kita tidak mendengarkan permohonannya." (Keluaran, 42, 21). Setelah mendengar perkataan para saudaranya, Yusuf justru terharu berkata, "Jangan takut, Allahmu dan Allah Bapamu telah memberikan kepadamu harta terpendam dalam karungmu." (Keluaran, 43, 23) "Akulah Yusuf, saudaramu, yang kamu jual ke Mesir. Tetapi sekarang, janganlah bersusah hati dan janganlah menyesali diri, karena kamu menjual aku ke sini, sebab untuk memelihara kehidupanlah Allah menyuruh aku mendahului kamu." (Keluaran 45, 5-6). Belas kasih yang dimiliki dan diterapkan Yusuf melampaui kecemburuan saudara-saudaranya dan kecemasan mereka bahwa Yusuf akan balas dendam. Ungakapan Yusuf ini menyatakan rencana Allah, karena rencana Allah itu dihayatinya dengan belas kasih.

Tanpa pengampunan, hidup tidak berbuah dan takkan dapat melahirkan kehidupan baru. Dengan pengampunan keluarga bersama menanggung kelemahan dan kesulitan saudara-saudari, merawat lukaluka hati. Pengampunan yang dihayati membangkitkan semangat baru dalam keluarga sehingga keluarga memiliki keberanian memandang ke depan penuh harapan. Yesus berpesan, "Hendaklah berbelas kasih, sama seperti Bapamu berbelas kasih." (Luk 6:36). Agar pesan ini hidup,

${ }^{10}$ Largus Nadeak, Topik-topik Teologi Moral..., hlm. 155.

${ }^{11}$ Paus Fransiskus, Bulla Misericordiae Vultus (Wajah Kerahiman), Roma 2015, no. 20. 
keluarga perlu mendengarkan dan merenungkan Sabda Allah, perlu berdiam diri, tenang dan damai di hati. Dengan demikian keluarga mampu menyelami belas kasih Allah dan menghayatinya hari demi hari. ${ }^{12}$

Resep tahapan menghayati kerahiman diberi oleh Tuhan, "Janganlah kamu menghakimi, maka kamu pun tidak akan dihakimi. Dan janganlah kamu menghukum, maka kamu pun tidak akan dihukum; ampunilah maka kamu akan diampuni. Berilah dan kamu akan diberi: suatu takaran yang baik, yang dipadatkan, yang diguncang dan yang tumpah ke luar akan dicurahkan ke dalam ribaanmu. Sebab ukuran yang kamu pakai untuk mengukur akan diukurkan kepadamu." (Luk 6:37-38). ${ }^{13}$

\section{Keadilan Proporsional}

Masyarakat penganut sistem paternalistik mengutamakan hormat pada "pater (bapak)", otoritas, orang tua, dan orang yang lebih tua. Dirasa adil kalau kebutuhan dan peluang dibagi dengan porsi yang lebih banyak pada orang tua dan yang dituakan atau lebih mendahulukan mereka. ${ }^{14}$ Dewasa ini masyarakat tetap menghoramati orang tua dan yang lebih tua tetapi masyarakat lebih menghormati orang yang memiliki integritas dan kreativitas tanpa melihat usia. Dirasa adil secara proporsional, kalau kebutuhan yang lebih banyak atau yang didahulukan adalah orang yang pantas, bukan karna usia biologis, otoritas, dan status.

Satu contoh praktis untuk mengenal keadilan proporsional dalam keluarga. Orang tua yang masih menghidupi pola keadilan tradisional akan membagi uang jajan untuk anaknya SMU sebanyak Rp 30.000, untuk SMP sebanyak Rp 20.000, dan untuk SD sebanyak Rp 10.000. Orang tua yang berkeadilan proporsional (sebanding) akan membagi uang jajan anaknya sesuai kebutuhan, mungkin untuk anak yang SD sebanyak Rp 30.000, untuk yang SMU Rp 20.000 dan untuk yang SMP sebanyak Rp 10.000. Penerapan keadilan proporsional melatih anggota keluarga menghayati belas kasih.

Keadilan Allah yang proporsional dan berbelas kasih kita temukan dalam beberapa ungkapan dalam Kitab Suci, secara khusus

${ }^{12}$ Misericordiae Vultus, no. 13.

${ }^{13}$ Misericordiae Vultus, no. 14.

${ }^{14}$ Richard Sinaga, "The Gospel of Family...", hlm 226. 
kita kenal dalam tiga perumpamaan: domba yang hilang, dirham yang hilang, dan anak yang hilang (Luk 15: 1-32). Dalam ketiga perumpaan ini, Allah diperkenalkan penuh kegembiraan mengampuni. Pesan berharga pada keluarga beriman bahwa belas kasihan merupakan kekuatan yang mengatasi dan mengalahkan masalah, sehingga mengalir kasih sayang dan kebahagiaan. ${ }^{15}$ Kesan sepintas tak adil meninggalkan 99 domba untuk mencari seekor yang hilang. Kesan itu bisa muncul karena cemas bahwa 99 domba kurang mendapat perhatian dan ditinggal. Pesan berharga dari perumpamaan ini adalah dalam kebersamaan yang memiliki keadilan berbelas kasih, satu pun jangan pernah hilang, yang 99 tidak merasa hilang ditinggal dan tidak merasa lebih benar, dan yang satu dicari dan ditemukan untuk mengalami perubahan dan kebaruan dalam kebersamaan. Kalau ada seorang yang hilang maka semua harus merasa kehilangan dan harus saling mencari.

Selesai memberi renungan singkat tentang perumpamaan domba yang hilang, di satu stasi, seorang ibu yang masih memiliki pola keadilan tradisional protes pada saya. Dia masih keberatan bahwa yang 99 ditinggalkan demi yang satu. Untuk menjelaskan perumpamaan ini lebih sederhana, saya tanya jumlah anak dari ibu tersebut. Dia memiliki anak 7 orang. Lalu saya tanya, "Seandainya salah seorang dari anakanak ibu sakit keras dan diopname di Rumah Sakit, apakah ibu menjaga 1 orang anak yang sakit dan meninggalkan yang 6 orang lagi di rumah?" Spontan ibu itu menjawab, "Jelas". Kemudian Ibu tersebut berhening batin, dan pelan-pelan dia memahami keadilan berbelas kasih. Anggota keluarga yang sakit, baik secara fisikis, psikologis, maupun spiritualis membutuhkan lebih besar perhatian dan belas kasih diberi oleh orang tua dan juga oleh saudara-saudari.

Suasana yang sering terjadi, bahwa perhatian orang tua lebih besar pada anaknya yang pintar, yang cantik, kurang pada anak yang agak lemah. Kadang kebanggaan orang tua lebih pada anaknya yang sukses, kurang pada anaknya yang kurang sukses walau sudah kerja keras. Orang tua yang menghayati keadilan yang berbelas kasih, seharusnya bangga dan menyapa semua anak secara adil proporsional, sehingga ada saatnya perhatian justru lebih besar pada anak yang kurang mampu secara intelektual, dan kurang sukses dalam perjuangan hidup.

15 Benitius Brevoort, "Yubileum Istimewa Kerahiman", dalam Persaudaraan, no. 2/XIV, April-Juni 2016, hlm. 13. 


\section{Menghayati Belas Kasih}

Mencermati pengalaman berkeluarga dalam hidup sehari-hari dan mendalami pesan Yesus jelas bahwa belas kasih hidup subur di keluarga yang saling mencari dan saling mempercayai. Jangan pernah tercabut daya mempercayai sesama anggota keluarga. Mungkin orang tua kecewa pada anaknya, tetapi orang tualah yang harus mempercayai anaknya. Demikian juga anak terhadap orang tua. Mungkin saja orang tua kurang cocok menurut pandangan anak, tetapi itulah orang tuanya, anak harus mempercayai orang tua. Walau orang tua temannya baik, itu orang tua teman, bukan orang tua sendiri. Keluarga sendiri dengan segala kelebihan dan kekurangannya adalah keluarga sendiri.

Peradaban kasih yang dipromosikan oleh Paus Yohanes Paulus II dalam Surat kepada Keluarga-keluarga, berdaya memperbaiki dan menyembuhkan akibat-akibat yang menyusahkan yang tersembunyi dalam hati keluarga, bagaikan luka yang menyakitkan. Belas kasih orang tua dan anggota keluarga mampu menyembuhkan luka-luka yang ada. Kemampuan itu efektif kalau hadir rahmat pengampunan dan rekonsiliasi ilahi yang selalu menjamin energi rohani untuk memulai sesuatu secara baru. Untuk itu keluarga perlu menjumpai Kristus di dalam Gereja lewat Sakramen Pengampunan Dosa dan Rekonsiliasi yang mengagumkan.16 Paus ini juga menggarisbawahi dalam Anjuran Apostolik Familiaris Consortio, bahwa penerimaan, pengampunan dan pengakuan timbal balik dalam keluarga sangat penting dalam hidup sehari-hari sehingga buah sakramen pertobatan dihayati. Hendaknya keluarga tidak putus asa tetapi tabah dan rendah hati mempercayakan diri kepada kerahiman Allah. ${ }^{17}$

Jelas belas kasih Allah bukan hal yang abstrak, mengawang, tetapi kenyataan akrab dan dapat disentuh. Ia mewahyukan kasih-Nya seperi kasih seorang bapa atau ibu yang tergerak sumsum hatinya demi anaknya sendiri. Kasih sayang Allah datang dari dalam diri-Nya seperti dari rahim seorang ibu, yang memberi kehidupan, melindungi,

16 Paus Yohanes Paulus II, Surat kepada Keluarga-keluarga, Roma 1994, hlm. 40, 49 .

17 Paus Yohanes Paulus II. Anjuran Apostolis Familiaris Consortio (Keluarga), Jakarta: Dokumentasi dan Penerangan KWI, 1993, no. 58. 
melahirkan, penuh keakraban, penerimaan, panjang sabar dan rela mengampuni. ${ }^{18}$

Menarik keyakinan dan pengalaman seorang ayah. Agar anakanak terlatih teratur dan tertib disepakati beberapa aturan. Mereka berusaha mengikuti aturan, tetapi kadang mereka berontak dan tidak mau ikut aturan, dengan variasi motivasi. Kadang juga terjadi situasi kucing-kucingan dengan orang tua, bahkan kadang mereka berbohong. Walau demikian, ayah tersebut berusaha mempercayai anak-anaknya. Suatu saat dia mengatakan pada anak-anaknya, "Saya tetap mempercayai kamu walau sepengetahuan saya dan terlebih tidak sepengetahuan saya, kamu tidak mengikuti aturan bahkan membohongi saya. Kebanggan tersendiri bagi saya bahwa saya bisa mempercayai anak-anak yang membohongi saya. Mempercayai orang baik adalah hal biasa, tetapi mempercayai orang yang membohongi menjadi lebih dari yang biasa." Sikap mempercayai yang diterapkan oleh ayah itu justru membuat anak-anaknya semakin terpercaya, dan tentu ayah tersebut tidak merasa terbebani mendampingi mereka justru bersuka cita mengemban tangguang jawabnya.

Tanggung jawab berkembang di kebersamaan kalau setiap anggota keluarga jujur dalam kelemahan dan juga dalam kekuatan. Penanaman nilai kejujuran mendapat perhatian dewasa ini. ${ }^{19}$ Orang jujur mengatakan kenyataan sesungguhnya. Anggota keluarga yang jujur akan terlibat secara murni dan tulus dan terus-menerus berusaha menganalisis dan memecahkan masalah. Anggota keluarga yang tidak jujur akan menyembunyikan kenyataan di dalam dirinya dan dengan ketidakjujuran itu dia mengelakkan tanggung jawab yang seharusnya diembannya. Orang yang terbiasa bertanggung jawab akan membentuk pribadi berintegritas. Orang yang berintegritas menyatakan (mewujudnyatakan) yang dikatakan dan yang dijanjikan.

Jiwa belas kasih dalam keluarga yang berkumpul dalam nama Yesus menjadikan Yesus dan daya belas kasih-Nya hidup dan berdaya di keluarga. Daya maaf berpengaruh kalau sesama anggota keluarga mau saling memuji dan meneguhkan kebaikan, saling mengingatkan dan mengoreksi kekurangan, dan terlebih saling mengakui kesalahan. Belas kasih subur di keluarga yang dengan hati jujur mengakui

18 Misericordiae Vultus, no. 6; Bdk. Benitius, "Yubileum Istimewa...", hlm. 12.

${ }^{19}$ Sekretaris Sinode VI KAM, Keadaan Keluarga Katolik..., hlm. 9, 101. 
kesalahan. Keluarga membutuhkan pertolongan rahmat, yang diberikan oleh Allah dalam kerahiman-Nya yang tak terbatas. ${ }^{20}$

Ilustrasi Stephen Covey sangat inspiratif untuk menolong keluarga hidup bahagia dan bersuka cita. Menurut Covey, bukan berat beban yang membuat manusia stress tetapi lamanya memegang beban tersebut. ${ }^{21}$ Orang harus meninggalkan beban kita secara periodik. Kekurangan yang jadi beban hendaknya tidak disimpan lama agar tidak membuat nadi batin pegal, tetapi sebaliknya cepat dilepas agar orang bahagia dan bersuka cita.

Teman saya yang ahli dalam konseling untuk mengatasi depresi mengatakan bahwa mayoritas penderita depresi akibat dari terlambat mengampuni orang yang dia rasa bersalah padanya, bahkan bukan hanya terlambat, tidak mau mengampuninya. Misalnya, bisa saja seorang isteri mengalami depresi karena menyimpan kesalahan suaminya. Suaminya sudah salah, lalu dia salah juga karena menyimpan kesalahan itu di dalam dirinya. Penyembuhannya adalah membangunkan the power of forgiveness yang sedang tidur di dalam diri.

Untuk menghayati belas kasih, hendaknya keluarga membuat perayaan kebersamaan. Kebersamaan rekreatif akan menyegarkan fisik dan hati, tetapi tidak boleh dilupakan kebersamaan rekolektif, kebersamaan berdoa. Doa bersama keluarga akan menjadikan setiap anggota keluarga tersambung secara rohani. Doa malam secara khusus akan membantu anggota keluarga mengadakan pemeriksaan batin. Ada saatnya tidak semua anggota keluarga bisa berkumpul, apalagi kalau anak sudah pergi merantau maka bagus juga bahwa keluarga

${ }^{20}$ Katekismus Gereja Katolik. Diterjemahkan oleh P. Herman Embuiru. Ende: Arnoldus, 1995, no. 1608.

21 Stephen Covey, Managemen Stress, https://www.kaskus.co.id, diakses 11 November 2017. Pada saat memberikan kuliah tentang manajemen stres Stephen Covey mengangkat segelas air dengan tangan kanan yang lurus ke depan, dan bertanya kepada para siswanya, "Menurut Anda, kira-kira seberapa beratnya segelas air ini?" Para siswa menjawab mulai dari 200 gram sampai 500 gram. Kemudian dia menjelaskan. "Ini bukanlah masalah berat absolutnya, tetapi tergantung berapa lama Anda memegangnya. Jika saya memegangnya selama 1 menit, tidak ada masalah. Jika saya memegangnya 1 jam, lengan saya akan sakit. Dan jika saya memegangnya 1 hari penuh, mungkin Anda harus memanggilkan ambulans untuk saya. Beratnya sebenarnya sama, tapi semakin lama saya memegangnya, maka bebannya akan semakin berat. Jika kita membawa beban kita terus menerus, lambat laun kita tidak akan mampu membawanya lagi." 
menentukan saat berdoa bersama di manapun mereka berada. Doa bersama akan menguatkan belas kasih dan kerinduan untuk saling mengampuni.

Keluarga hendaknya mengutamakan pengalaman berahmat, bukan menonjokan aturan dan hukuman. Paus Fransiskus menekankan pentingnya "auto kritik" terhadap pendekatan yang tidak memadai atas masalah perkawinan dan keluarga. ${ }^{22}$ Kebijakan pastoral hendaknya membantu umat untuk menemukan cara yang wajar agar mengambil bagian dalam komunitas gerejawi, dan untuk mengalami bagaimana disentuh oleh belas kasih yang berlimpah, tanpa syarat dan murah hati. 23

Mencintai keluarga dengan adil dan belas kasih akan menjadikan keluarga berdaya hidup di antara situasi nyata yang menantang dan krisis yang sedang berjalan dan akan tetap ada. Daya belas kasih akan menyuburkan rahmat sakramen perkawinan dan sakramen lain dalam keluarga yang menjadikan setiap anggota mengenal kelebihan dan kekurangan dan yang lebih penting akan mampu berangkat ke hidup berkeluarga yang selalu terbuka membarui keluarga dalam rahmat Allah.

Paus Fransiskus memunculkan epikeia yang disuarakan oleh St. Thomas dari Aquino, untuk memahami situasi keluarga saat ini, "Sungguh benar bahwa hukum-hukum umum yang disusun untuk mengusahakan kebaikan tidak dapat direndahkan atau diabaikan, namun dalam perumusannya, hukum-hukum itu tidak dapat secara absolut berlaku sama untuk situasi-situasi tertentu. Pada saat yang sama, harus dikatakan bahwa, persis karena alasan itu, apa yang menjadi bagian dari discernment praktis atas situasi khusus tidak dapat diangkat pada tingkat sebuah aturan." 24

22 Amoris Laetitia, no. 37.

${ }^{23}$ Amoris Laetitia, no. 297.

${ }^{24}$ Amoris Laetitia, no. 304. 


\section{Penutup}

Dengan menghayati “I love my family!", keluarga menjadi pusat mensyukuri pengalaman yang berhasil dan pusat pelarian di kala gagal, sehingga peradaban belas kasih hidup subur. Ungkapan Paus Frasiskus di paragraf terakhir Amoris Laetitia,

Tidak ada keluarga jatuh dari surga dalam bentuk yang sempurna; keluarga perlu terus menerus bertumbuh dan dewasa dalam kemampuan untuk mencintai... Kita semua dipanggil untuk terus mengarah kepada sesuatu yang lebih besar dari kita dan keluarga kita, dan setiap keluarga harus terus merasakan dorongan ini. Marilah kita berjalan sebagai keluarga, marilah kita terus berjalan bersama. (...) Semoga kita tidak patah semangat karena keterbatasan kita, atau berhenti mencari kepenuhan kasih dan kesatuan dengan Allah yang menuntun kita. ${ }^{25}$

Berbelas kasih merupakan hak (keadilan) yang sebaiknya diperoleh oleh setiap anggota keluarga, terlebih oleh anggota yang mengalami tantangan dan masalah. Keluarga yang berada dalam masalah hendaknya juga mendapat belas kasih dari persekutuan keluarga gerejawi, bukan sebaliknya menghukum dengan aturan yang bertentangan dengan hukum Gereja Kudus yang berlaku.

${ }^{25}$ Amoris Laetitia, no. 325. 
Largus Nadeak, Mencintai Keluarga: Menghayati Keadilan dan Belas Kasih

\section{DAFTAR PUSTAKA}

Brevoort, Benitius, "Yubileum Istimewa Kerahiman", dalam Persaudaraan, no. 2/XIV, April-Juni 2016.

Cahil, Lisa Sowle and Mieth, Dietmar (ed). The Family - Concilium 1995/4, Maryknoll: Orbis Books, 1995.

Covey, Stephen, Manajemen Stres, https:// www.kaskus.co.id, diakses 11 November 2017.

Dokumen Konsili Vatikan II. Diterjemahkan oleh R. Hardawiryana. Jakarta: Dokumentasi dan Penerangan KWI - Obor, 1993.

Eminyan, Maurice. Teologi Keluarga, Yogyakarta: Kanisius, 2001.

Groenen, Cletus. Perkawinan Sakramental, Anthropologi dan Sejarah Teologi, Sistematik, Spiritualitas, Pastoral, Yogyakarta: Kanisisus, 1993.

Jersild, Paul dan Johnson, Dale (ed). Moral Issues and Christian Respons, New York: The Dryden Press 1988.

Katekismus Gereja Katolik. Diterjemahkan oleh P. Herman Embuiru. Ende: Arnoldus, 1995.

Nadeak, Largus. Topik-topik Teologi Moral Fundamental, Memahami Tindakan Manusiawi dengan Rasio dan Iman. Medan: Bina Media Perintis, 2015.

Paus Fransiskus, Bulla Misericordiae Vultus (Wajah Kerahiman), Roma 2015.

Paus Fransiskus, Anjuran Apostolik Paska Sinode Amoris Laetitia (Kegembiraan Cinta), Roma 2016.

Paus Yohanes Paulus II. Anjuran Apostolis Familiaris Consortio (Keluarga), Jakarta: Dokumentasi dan Penerangan KWI, 1993.

Paus Yohanes Paulus II, Surat kepada Keluarga-keluarga, Roma 1994.

Sekretaris Sinode VI KAM, Instrumentum Laboris dan Makalah-makalah, Keluarga Katolik sebagai Gereja Kecil. Pematangsiantar, 2016.

Sekretaris Sinode VI KAM, Keadaan Keluarga Katolik di Keuskupan Agung Medan, Hasil Penelitian dan Jajak Pendapat. Pematangsiantar, 2016 